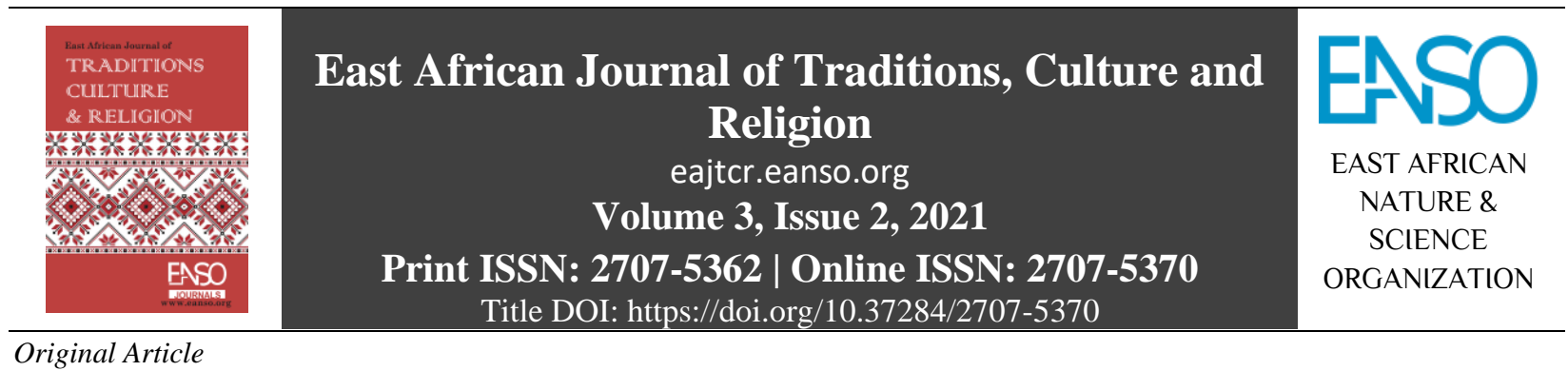

\title{
Epistemological Base of African Traditional Herbal Medicine Among Primary School Teachers in Uganda.
}

\author{
Disan Kuteesa, PhD \\ ${ }^{1}$ Head of Department, Foundations of Education, Kyambogo University, P.O. Box 1, Kyambogo, Kampala, Uganda. \\ Author Correspondence Email: disanmugenyi75@gmail.com.
}

Article DOI: https://doi.org/10.37284/eajtcr.3.2.376

\section{Date Published: ABSTRACT}

05 August 2021 There is a noticeable usage of African Traditional herbal medicine in the treatment of physical and metaphysical diseases. This is largely due to the

Keywords: perceived high costs of orthodox medicine and the feeling that traditional herbs are more dependable. This research established the epistemological Epistemology, underpinnings of African traditional herbal medicine among primary school Base, teachers in the Central Region of Uganda. The researcher used interviews, Traditional, document analysis and focus group discussions to collect data from different African traditional herbal medicine is based on testimonial seeming, perceptual Teachers. epistemological theory which can appropriately explain the basis of African Traditional herbal medicine in schools is the Bucket Theory of mind as advocated for by Karl Popper. The study recommends Poppers' falsification theory in the operations of primary school teachers as a measure to do away with falsity content in the usage of traditional herbal medicine in schools.

\section{APA CITATION}

Kuteesa, D. (2021). Epistemological Base of African Traditional Herbal Medicine Among Primary School Teachers in Uganda. East African Journal of Traditions, Culture and Religion, 3(2), 43-51. https://doi.org/10.37284/eajtcr.3.2.376.

\section{CHICAGO CITATION}

Kuteesa, Disan. 2021. "Epistemological Base of African Traditional Herbal Medicine Among Primary School Teachers in Uganda". East African Journal of Traditions, Culture and Religion 3(2), 43-51. https://doi.org/10.37284/eajtcr.3.2.376.

\section{HARVARD CITATION}

Kuteesa, D. (2021) "Epistemological Base of African Traditional Herbal Medicine Among Primary School Teachers in Uganda", East African Journal of Traditions, Culture and Religion, 3(2), pp. 43-51. doi: 10.37284/eajtcr.3.2.376.

\section{IEEE CITATION}

D. Kuteesa, "Epistemological Base of African Traditional Herbal Medicine Among Primary School Teachers in Uganda", EAJTCR, vol. 3, no. 2, pp. 43-51 Aug. 2021. 


\section{MLA CITATION}

Kuteesa, Disan. "Epistemological Base of African Traditional Herbal Medicine Among Primary School Teachers in Uganda". East African Journal of Traditions, Culture and Religion, Vol. 3, no. 2, Aug. 2021, pp. 43-51, doi:10.37284/eajtcr.3.2.376.

\section{INTRODUCTION}

Epistemology inquiries into the possible nature origin, scope, validity, and limits of human knowledge. Knowledge is the awareness and understanding of particular aspects of reality (Lemons, 2007). However, from classical accounts, for anyone to lay claim to knowledge, such claims must be true and believed with justification. Therefore, knowledge is sometimes defined as justified true belief, because to know something, one must believe in it, one's belief must be true and one's reason for believing it must be satisfactory in the high of some standard (Ayer, 1956). Man's search for knowledge and his desire to understand nature and the universe are perennial tasks (Alston, 1989). Everything which people philosophize about depends on knowledge; in fact, historians of science have produced a flourishing literature around the idea that even the most basic elements of knowledge-making have histories; hence epistemology examines how the knower may proceed to identify candidates of knowledge.

African traditional herbal medicine has been used long before recorded history, as early as 3000 BC and people in different parts of the world tend to use the same or similar plants for the purpose, but there is no firm ground on which the practices are grounded. Teachers tend to use traditional herbal medicine however their epistemological base is not known, if known it, is not documented.

In contrast, western medicine which is also applied in schools, is anchored in the scientific method with known dosage, and steps for its discovery which include: Formulation of questions, or Finding out how a drug to cure a disease can be designed, Hypothesis, Prediction, Testing, Analysis, Replication, External review, Data recording and sharing of knowledge, consequently western medicine is discovered. A case in point is the process of producing quinine tablets, which is well known and side effects are well established after experimentation and testing.
The advocates of western medicine concede its overwhelming superiority in unravelling the microbiological mechanism by which fever affects the physiological processes and how quinine destroys the hostile pathogens in order to rectify cellular disorders. Hence school doctors and nurses rely on both laboratory tests and observation symptoms presented by the sick pupils on examination. On the other hand, primary school teachers treat fever using bitter leaves without a known dosage and ingredients. The sick pupil is given a concoction whose quantity and quality are not known by western standards. Teachers have only direct visuals as well as tactile observations and the pupil description of how he feels. Consequently, teachers proceed to draw conclusions on how the body's condition has deviated from that of a healthy balanced state. This explains why some western medical practitioners perceive African traditional herbal medicine as a product of hocuspocus or primitive thinking, where, if a pupil is cured by means of herbs, they assume it is by epistemic luck or placebo effect (Hutchings, 1996).

Some western medical practitioners assume that African traditional herbal medicine does not derive from reliable cognitive mechanisms but it is based on shakeable convictions. The fact that African traditional herbal medicine has thrived up to the $21^{\text {st }}$ century is a testimony to its effectiveness in both prevention and treatment of diseases but the deficiency is that people are making a claim that herbals are real and widely used in schools alongside western medicine yet the approach of knowledge on which it is based is not known. How do primary school teachers get herbal knowledge? How do they come to know, for example, that bitter leaves have medicinal and curative properties? What is the origin of African herbal medicine among Primary school teachers? Which theory do they use? Such questions need to be answered because teachers' claims to knowledge are not based on scientific reasoning or Experimentation.

To be certain about an epistemic claim is to assert that such a claim is either immune to scepticism or more warranted than any sceptical consideration. So why primary school teachers accept and use African 
traditional herbal medicine to treat diseases among children alongside western medicine whose base is well established? Henceforth, the establishment of the epistemological basis of African traditional herbal medicine for Primary school teachers is likely to elevate herbal medicine to the level of western medicine which is internationally recognized.

\section{Statement of the Problem}

Traditional herbal medicine is developed using Larmarkinism and Deontological justification. It is accepted and respected worldwide alongside western medicine. Traditional herbals do not go through the rigorous testing and experimentation that are normally accorded to western medicine, so all teachers who use African traditional herbal medicine have organismic and subjective knowledge, contrary western medicine is objective knowledge, procedural, adversarial, moreover in the third world of knowledge as put by Karl Popper (1960).

The principal question this study addressed was. Why is African Traditional herbal medicine used and accepted by primary school teachers yet its epistemological base is not known and documented? The dialectical interplay between the flux of ontological dialectics and the demand for axiological peace of African traditional herbal medicine perpetuated this study.

\section{THEORETICAL FRAMEWORK}

To accomplish the study's purpose, I grounded this investigation on Popperian falsification theory. Popper (1972) is generally credited for having provided improvements in the understanding of the scientific method. Popper's falsifiability theory is a required characterized for a scientific theory. Popper didn't believe in the possibility of attaining the ultimate truth, he asserts that people's understanding can grow and expand. Therefore, people should try to solve their problems by the process of elimination, this involves something approaching adequacy in their tentative solution and popper proposed the formula

$\mathrm{P}_{1} \longrightarrow \mathrm{TT} \longrightarrow$ EE - $\mathrm{P}_{2}$ (Popper, 1972, p. 144)
Hence to get knowledge, there must be a problem $\left(\mathrm{P}_{1}\right)$, a theory is later developed, then error elimination (EE) comes in and a new problem $\left(\mathrm{P}_{2}\right)$ crops up (Popper 1972). Because Popperian views discussed above are greatly connected to the scientific method which has led to the production of western medicine, I was therefore emboldened to seek out the diverse and ranging viewpoints, Primary school teachers hold in relation to the origin of their traditional herbal medicine.

\section{RESEARCH DESIGN}

A qualitative approach was used to capture narratives, opinions, comments and views from primary school teachers who use African traditional herbal medicine to treat sick children Qualitative studies aim to improve the understanding of phenomena through human experiences (Devers \& Frankel, 2000; Myers, 2000; Merriam, 2002). Furthermore, in qualitative research, emphasis is placed more on the way in which the individual interprets his or her social world (Bryman, 2008).

The qualitative approach enabled the researcher to capture voices on the experiences of teachers with herbal knowledge. As such experiences of teachers were captured since the goal of qualitative research is to examine how things look from different vantage points (Taylor \& DeVault, 2015; Myers, 2007). More so, using a qualitative approach enabled the researcher to connect with the participants and see the world from their own point of view (Corbin \& Strauss, 2015; Patton, 2002).

\section{Location of the Study}

The study was conducted in Mpigi District, this was selected by the researcher because its Government schools with children from poor families and teachers use African traditional medicine to treat most of the diseases.

\section{Target Population}

The target population of the study was Primary school teachers with African traditional herbal knowledge. The total population size of teachers is not documented due to the fact that the schools have employed teachers on a private basis because of a ban on staff recruitment in many schools. 


\section{Sample Size for Individual Interviews}

The sample size was 18 primary school teachers. This number was subject to increase or reduction in case the point of saturation was reached (Hagaman \& Wutich, 2017). Saturation occurs when adding more participants to the study does not result in additional perspectives or information (Guest \& Macqueen, 2008; Guest, Bunce \& Johnson, 2006).

\section{Sampling Techniques}

Purposive sampling was used for selecting study participants (Kothari, 2004; Silverman, 2016; Taylor \& DeVault, 2015). Purposive sampling was used to select teachers who have herbal knowledge and use it to treat sick children.

Table 1: Statistics on Presence of Primary School Teachers with Herbal Knowledge in Mpigi District

\begin{tabular}{|c|c|c|c|}
\hline School & $\mathbf{S} / \mathbf{N}$ & $\begin{array}{l}\text { Pseudo Names Teachers with } \\
\text { Herbal Knowledge }\end{array}$ & Source of Knowledge \\
\hline Kamengo Primary School & $\begin{array}{l}1 \\
2 \\
3 \\
4 \\
5 .\end{array}$ & $\begin{array}{l}\text { - } \mathrm{AA} \\
\text { - } \mathrm{AB} \\
\text { - } \mathrm{AC} \\
\text { - } \mathrm{AD} \\
\text { - } \mathrm{AE} \\
\end{array}$ & $\begin{array}{ll}\text { - } & \text { Family background } \\
\text { - } & \text { Family background } \\
\text { - } & \text { Relative } \\
\text { - } & \text { Family background } \\
\text { - } & \text { Family background } \\
\end{array}$ \\
\hline Ggori Primary School & $\begin{array}{l}1 \\
2 \\
3 \\
4 \\
5\end{array}$ & $\begin{array}{ll}\text { - } & \mathrm{AB} \\
\text { - } & \mathrm{BB} \\
\text { - } & \mathrm{BC} \\
\text { - } & \mathrm{BD} \\
\text { - } & \mathrm{BE} \\
\text { - } & \mathrm{BF}\end{array}$ & $\begin{array}{ll}\text { - } & \text { Family background } \\
\text { - } & \text { Relative } \\
\text { - } & \text { Family background } \\
\text { - } & \text { Plant communication } \\
\text { - } & \text { Radio Programs }\end{array}$ \\
\hline Kanyike Primary School & $\begin{array}{l}1 \\
2 \\
3 \\
4 \\
5\end{array}$ & $\begin{array}{ll}-\mathrm{CA} \\
\text { - } \mathrm{AB} \\
\text { - } \mathrm{CC} \\
\text { - } \mathrm{CD} \\
\text { - } \mathrm{CE}\end{array}$ & $\begin{array}{ll}\text { - } & \text { Family background } \\
\text { - } & \text { Family background } \\
\text { - } & \text { Family background } \\
\text { - } & \text { Plant communication } \\
\text { - } & \text { Radio programs }\end{array}$ \\
\hline
\end{tabular}

Source: Designed by the Researcher (2019).

Table 1 shows the sample statistics of the primary school teachers with herbal knowledge.

\section{Data Collection Methods}

One qualitative method of in-depth interviews was used in the study. In the same way, non-participant observation was also used to supplement the interviewees' responses. In this case, observation was used to identify silent values, expressions and gestures during the process of the face-to-face interviews (Hennink, Hutter \& Bailey, 2011; Silverman, 2016).

\section{Research Instrument}

The research instrument that guided the study comprised of the interview guide which was designed in such a way that it included research questions that were linked to the objective of the study (Hennink et al., 2011). The interview guide had open-ended questions that were in line with the study objective. The question items in the interview guide were used to obtain narratives of primary school teachers.

Data were collected from the individual participants using tools and devices such as a voice recorder and writing logistics. According to Matheson (2007), a voice recorder was used for audio recordings to capture voices of the primary school teachers with African traditional herbal knowledge. This was needed for transcription purposes. Field notes were also taken to supplement voice recordings by ensuring correctness in the recorded data. 


\section{Data Collection Procedures}

The researcher sought permission from the participants who were humbly requested for their voluntary participation in the study. Those who were willing to provide the necessary information were interviewed and their responses kept confidential and only used for the purpose of the study (Silverman, 2016; Creswell, 2003). Arrangements for the meeting were done by the researcher and the participant as to where and when the interview was to be conducted. In the same way, meetings were held at the convenient time of the interviewee and the interviews took 30-40 minutes (Kothari, 2004; Creswell, 2003).

\section{PRESENTATION AND DATA ANALYSIS}

A total of 14 (Fourteen) teachers were interviewed and gave the following responses in relation to the epistemic source of African traditional herbal medicine in primary schools in Uganda.

Table 2: epistemic source of African traditional herbal medicine

\begin{tabular}{ll}
\hline Source & Percentage \\
\hline Parents, relatives, family & 11 teachers $-(95 \%)$ \\
Plant communication & 02 teachers $(02 \%)$ \\
Radio Programs & 02 teachers $(02 \%)$ \\
\hline
\end{tabular}

Eleven teachers reported that they acquire their herbal knowledge from their family background. It was established that five (05) teachers from Kamengo, three (03) from Ggori and three (03) from Kanyike come from families where herbal medicine is given emphasis, implying that they were born in a laboratory and grew up in a laboratory and acquired herbal medicine. A case in point is a famous teacher ' $A A^{\prime}$ ' who reported that in his school, he has a child born with HIV and treats him using leaves of strawberry. The leaves are squeezed and mixed with water; the mixture is taken to treat skin infections. The product is boiled for some time and the child takes a mug three times a day. The teacher explicitly noted that he acquired herbal knowledge from a famous herbalist who treats HIV related disease. By implication, the elements of observation and perception were employed and the teacher acquired herbal knowledge.
Teacher ' $A B$ ' gave instances where he squeezes bitter leaves and add some water, the product is boiled for about ten minutes, the children with fever take a cup and within one day the temperature must have decreased. Further, the teacher 'AC asserted that ' when pupils get wounds especially after sports and digging; the teacher squeeze the leaves of blackjack and put on the wounds. This is done to kill the germs and after a few days, the wound heals. Notably, the teachers emphasized that all their herbal knowledge was acquired from their relatives whom they used to stay with when they were still young.

In a similar manner, Teacher ' $A B$ ' from Ggori Primary school, testified that his knowledge was passed to him from his family orally, he had this to say:

"My father was a famous herbalist; actually, that was his source of income. I used to work with him because I was a day student at O' level. I used to do a lot of things like picking herbs. By the time he died in 2012, I had learned a lot. So, when I became a teacher, I always refer to the knowledge, I acquired."

Two teachers (02), one from Kanyike Primary school and another from Ggori Primary school reported that radio programmes have exposed them to a variety of herbal medicine and how it is administered. In particular, Teacher 'BC' gave an example of pupils who come to school with a stomach ache, he squeezes the leaves of aloe vera which he mixes water and boil for about five minutes. The concoction helps to treat stomach ache and fever. He claimed that he acquired herbal knowledge from one of the radio programmes. However, the point to be noted here is that such herbal knowledge possessed by the teachers is undigested; the teachers could not explain why leaves are squeezed and the mixture given to sick children.

Basing on the above, the teacher's epistemological knowledge is acquired through Testimonial seemings, Perceptual seemings and Memorial seemings. Their minds resemble a container, a kind of bucket, in which perceptions and knowledge accumulate. In the philosophical world, this theory is better known under the more dignified name of the tabula rasa theory of mind.

47 | This work is licensed under a Creative Commons Attribution 4.0 International License. 
The mind is believed to be an empty state upon which the senses engrave their messages. The most important thesis of the bucket theory of mind is that people learn most, if not all what they know through the entry experience into the sense openings. Therefore, based on the foregoing, it is evident that the mentioned teachers do not have a standard of certainty in regard to herbal knowledge, but they believe in past experiences teachers need to know that in the whole field of knowledge, there is nothing like absolute certainty. All knowledge should be conjectural; all the work should be fallible. It was established that teachers are not concerned with the ontology of their herbal medicine and its functionality. They do not know the underlying real entity and the physiological manifestations of their treatments. Teachers do not have the World 3 of traditional herbal knowledge, thus knowledge of logical contents, books, and libraries to mention but a few.

On the other hand, two (2) teachers, one (01) from Ggori and another from Kanyike Primary school reported that plants communicate. They reported that whatever God created is medicinal and in order to establish which plant is medicinal, they consider the features and organs of a plant. A plant organ that resembles a human organ is medicinal. Teacher 'CE' had this to say:

"When God created the world, He wanted man to have a good life. A plant organ that looks like a human organ is medicinal. A case in point is soursop. It resembles a human heart and it is used to treat heart-related diseases. Also, sourness is associated with medicine, we usually apply bitter leaves to treat fever among our children."

Based on the foregoing, the two teachers reported so have acquired herbal knowledge from plant communication; they believe that some plants communicate to them through visual imagery. This is in line with the method of conjectures and refutation as discussed by Popperian epistemology.

The findings are also in support of Genesis 1:29, "that God himself left us with clues to what plants are most beneficial to cure specific ailments. However, this idea may look superstitious and mere folklore, but the home truth is that physical or chemical elements of plant which resemble human elements are medicinal. However what teachers should know is that all knowledge is gained by starting with the conjectured process, but they need falsifiability to find out whether logical consequences are acceptable or whether they have undesirable effects. What teachers call plant communication is inclined to the method of conjectures and refutations as explained by Karl Popper (1966) or the trial-and-error method. The fault with their assertion of Plant communication is the absence of repeated varied attempts until success or failure comes. Traditional Herbal knowledge for primary school teachers should be subjected to testing and experimentation.

Teachers need sensitization thus, they live by values, traditions and myths which are embedded in literature and studies by humans. However, a society that loses the capacity to subject these myths and traditions to imaginative criticism will die. This is the task which Karl Popper (1966), undertook in his assertion of the Objective Knowledge. Karl Popper introduced the three Worlds because he wanted to be able to analyse the interaction among the material world (World 1), Mental processes (World 2) and the Cultural objects produced by the human mind (World 3).

Popper's destination between the Three Worlds of knowledge can easily help primary school teachers to reconstruct the notion of Objective Knowledge which is lacking in their operations as teachers, helping pupils to learn well. Henceforth, other than basing herbal medicine on plant organs, teachers need fallible and shareable assertions that are defensible by criticisms and empirical tests.

The reason for this is that our traditional heritage may contain a dangerous mixture of elements and if they don't maintain the effort to eliminate error and confusion, the risk is ever-present and that the bad will drive out the good so that teachers should assess, adjust their opinions based on assessment, and then reassess as well as change their opinions again and re-adjust Traditional herbal medicine in primary schools.

\section{RECOMMENDATION}

In view of the above discussion and observations, the following recommendations have been proposed 
to be affected by teachers in Primary schools in order to promote Traditional Herbal Medicine and elevate it to the level of western medicine.

Popperian Falsification Theory in the acquisition of African Traditional herbal medicine. There is evidence that plant organs and properties that resemble human organs and properties are medicinal. However, teachers need to search for a revised disciplinary matrix, a revision that will allow the elimination of at least pressing anomalies. What teachers call African traditional medicine should be authenticated, they need to rely heavily on Popper's three World`s ontology.

African Traditional herbal medicine in Primary Schools should be a tested, evaluated and surviving structure of information that is developed by living systems. Poppers' ontology will transcend conflicts among teachers who think that African traditional herbal medicine is cultural and psychological. Poppers' theory of Objective Knowledge, if emphasized, will breathe fresh life into the study of Values, Myths and Traditions which are present in the operations of many Primary School Teachers. Teachers should view the universe as an old book from which the first and last pages have been lost, neither the begging nor the end is known, hence teachers have Knowledge of a part, not the whole. Hence, Modification and Improvements which are necessary elements in Western medicine should also be emphasized in their operations as Primary school teachers.

Sensitization of Primary School teachers to start herbal gardens. Teachers should be sensitized and trained to offer first Aid to children. $85 \%$ of the rural population in Uganda use herbal medicine due to the comparative advantage of accessibility, affordability reliability and cultural sensitivity. Teachers should get guidance from the National Council of Traditional Herbalists Association (NACOTHA) and start an herbal garden and eventually their role should be to give First Aid and refer children to Western-trained Doctors and Nurses. Teachers may deal successfully with diseases every day just like other people, but in instances where there are complicated cases of Fever, Cough, Broken bones among others, their operation should be of this nature.

The Recommended Role of Primary School teachers in relation to African Traditional Herbal Medicine

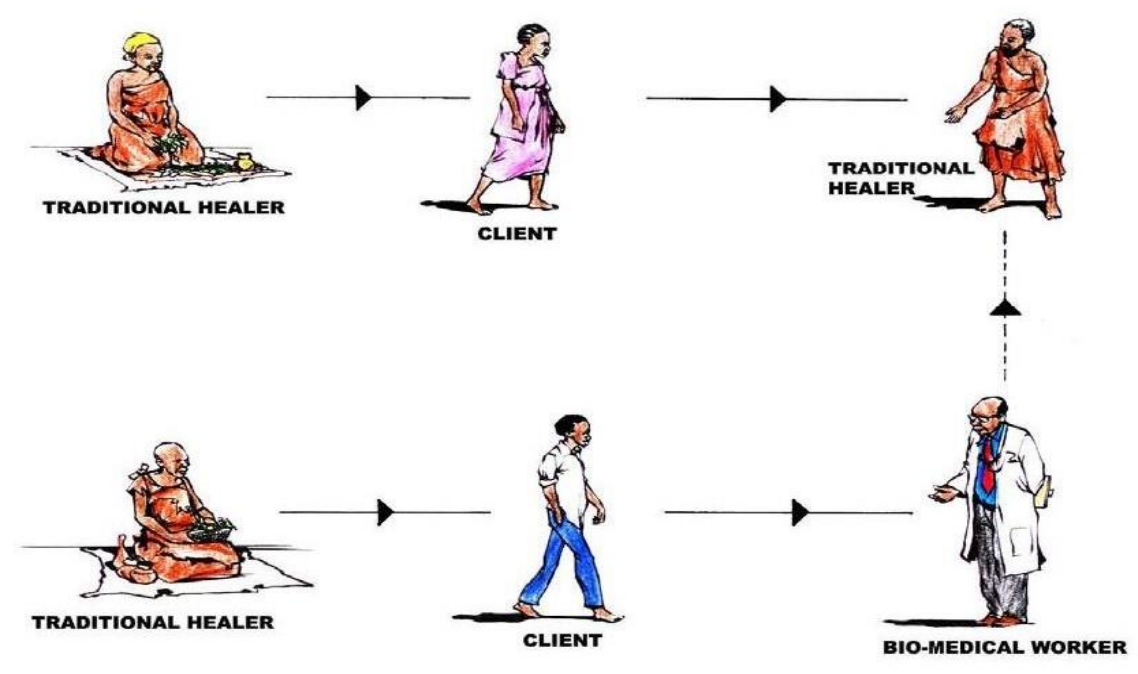

Further, all plants in the herbal garden must be selected by teachers with the help of NACOTHA officials. This will help to avoid dangerous plants which may be applied and harm students or plant which may have worked out of epistemic luck

\section{GENERAL CONCLUSION}

The role of Philosophy is to rationally, critically and systematically examine beliefs in a view of ascertaining their reasonableness. In addition, the fundamental objective of epistemology is to

49 | This work is licensed under a Creative Commons Attribution 4.0 International License. 
inculcate in humans the desire to subject every idea, however self-evident to rigorous scrutiny.

What Primary School teachers call Traditional herbal knowledge from radio Programmes, Friends, Family members is; Memorial seemings, Testimonial seemings and Perceptual seemings. In addition, what teachers call Plant Communication is the method of Conjectures and Refutation as advocated for, by Karl Popper. Hence the epistemological base for primary school teachers shares common traits with some litanies of western epistemologists like Karl Popper. The process of acquiring herbal medicine for primary school teachers is beclouded with terms from western epistemology like Memorial seemings, Testimonial perpetual seeming's and the theory of Conjectures and Refutations.

The study, therefore observes that though African Traditional Herbal Medicine in schools is not on the same explanatory pedestals with Western medicine, it is not primitive as ascribed by same intellectualists, but should instead be modified and improved. The bottom-most position is that African Traditional Herbal Medicine should be subjected to the testing process to avoid post hoe ergo propter hoe in the usage of Traditional Herbal Enterprise. Diagram to illustrate the right definition of Africa Traditional Herbal Medicine in schools

\section{Table 3: African Traditional Herbal Knowledge}

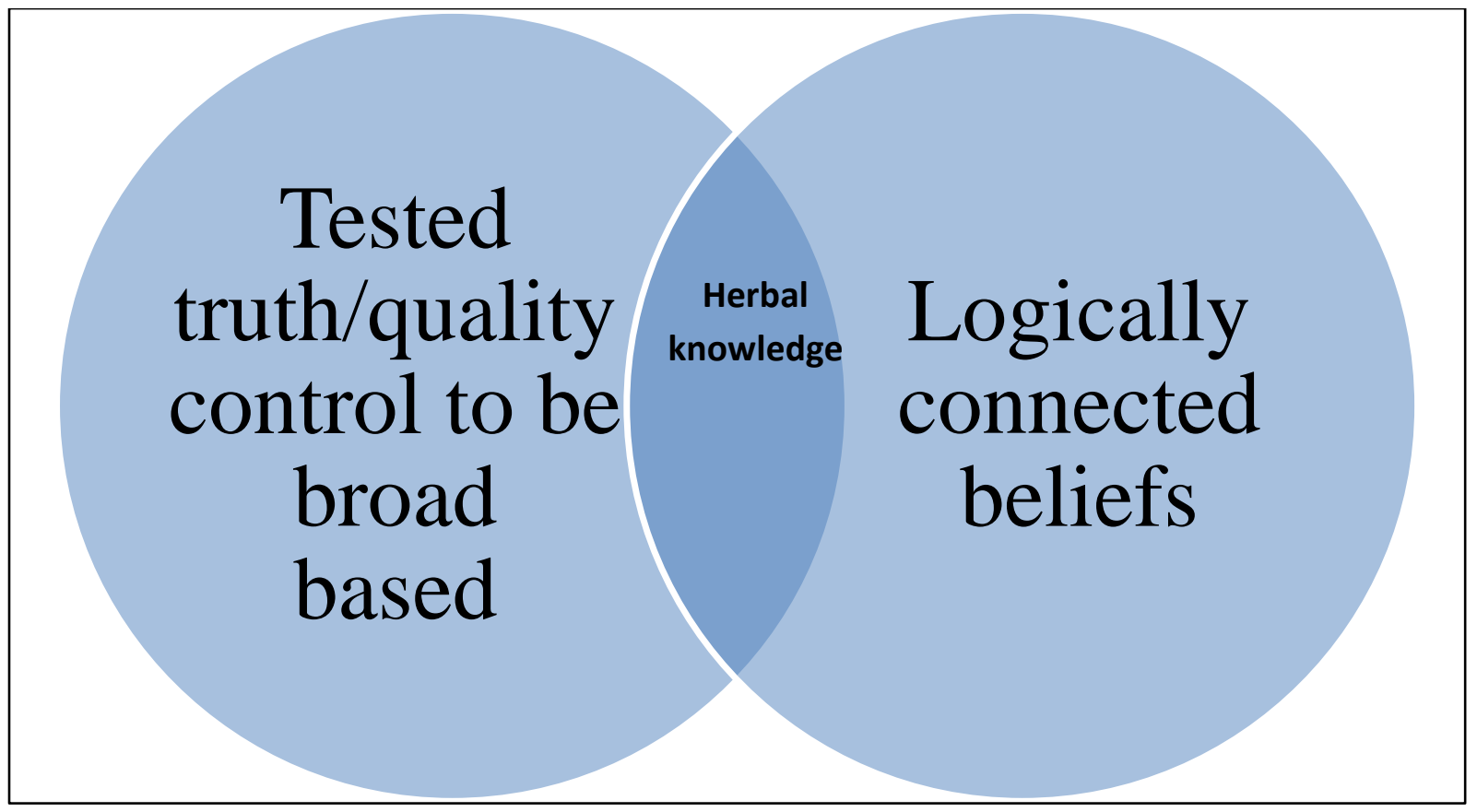

African traditional herbal medicine should be a set of constructions and empirical modes that together constitute a holistic non-reductionist way of body functioning. The conclusion is in line with the modern versions of Plato's definition which states that people's beliefs wound only count as knowledge when they are in accord with objective facts, and when the person who holds the beliefs has evidence of justification for it. Teachers should go beyond the range of sceptical doubts.
Teachers should start from Perceptual knowledge, Testimonial knowledge or Memorial knowledge but should actively develop into rational knowledge thus emphasizing contingent truth in the acquisition of African Traditional Herbal Medicine in Primary schools. 


\section{REFERENCES}

Ayer, A. J. (1956). The problem of knowledge. Penguin books.

Alston, W. P. (1985). Epistemic Justification and Essays in the Theory of Knowledge. Cornell University Press.

Bryman, A. (2008). Social Research Methods, $4^{\text {th }}$ Edition. Oxford University Press.

Creswell, J. C. (2003). Research Design, Qualitative, Quantitative and Mixed methods approach ( ${ }^{\text {nd }}$ Ed). Lincoln, Nebraska: University of Nebraska.

Devers, K. J., \& Frankel, R. M. (2000). Study Design in Qualitative research, study sampling and Data collection strategies. Education for Health, 13, 263-271.

Guest, G., Bunce, A., \& Johnson, L. (2006). How many interviews are enough? An experiment with data saturation and variability. Field methods, 18(1), 59-82.

Hennink, M., Hutter, I., \& Bailey, A. (2011). Qualitative Research Methods. Los Angeles: Sage.

Hagaman, A. K., \& Wutich, A. (2017). How many interviews are enough to identify metathemes in multisited and cross-cultural research? Another perspective on Guest, Bunce, and Johnson's (2006) landmark study. Field methods, 29(1), 23-41.

Hutchings, A. (1996). Zulu Medicinal Plants. Natal University Press. Pietermaritzburg.

Kothari, C. R. (2008). Research Methodology. Methods and Techniques. 2nd Edition. New Delhi: New Age International Publishers.

Lemos, N. (2007). An Introduction to the theory of Knowledge. Cambridge University Press.

Matheson, J. L. (2007). The Voice Transcription Technique: Use of Voice Recognition Software to Transcribe Digital Interview Data in Qualitative Research. Qualitative Report, 12(4), 547-560.
Merriam, S. B. (2002). An introduction to qualitative research. In Merriam S. B. \& Associates (Eds) Qualitative research in Practice: Examples for discussion and analysis. San Francisco. CA: Jossey -Bass.

Myers, M. (2000). Qualitative research and Generalizability questions; Standing Firm with Proteus: The qualitative Reports, 4(3), https//doi org/10.46743/2160-3715/2000/2925.

Popper, K. R. (1966). The Open Society and Its Enemies: The Spell of Plato. Volume I. George Routledge and Sons.

Popper, K. (1972). Objective Knowledge, An evolutional Approach. Oxford University Press.

Silverman, D. (Ed). (2016). Doing Qualitative Research $3^{\text {rd }}$ Edition. Sage London.

Silverman, D. (2006). Interpreting qualitative data Methods for analysing Talk and Text and Interaction. $3^{\text {rd }}$ Edition. Sage. London.

Sofowora, A. (1993). Medicinal plants and traditional medicine in Africa Spectrum books LTD. Ibadan, Nigeria, 289.

Taylor, S., \& Devault, M. (2015). Introduction to qualitative research Methods. John Wiley and Sons Inc. New Jersey. 